\title{
Emergency obstetric hysterectomy: experience at a tertiary care centre in Central India
}

\author{
Jayashree Mulik, Tanvi Vibhute*
}

Department of Obstetrics and Gynecology, Government Medical College and Hospital, Nagpur, Maharashtra, India

Received: 13 June 2019

Accepted: 09 July 2019

*Correspondence:

Dr. Tanvi Vibhute,

E-mail: drtanvivibhute@yahoo.com

Copyright: () the author(s), publisher and licensee Medip Academy. This is an open-access article distributed under the terms of the Creative Commons Attribution Non-Commercial License, which permits unrestricted non-commercial use, distribution, and reproduction in any medium, provided the original work is properly cited.

\begin{abstract}
Background: Obstetric hysterectomy is an important procedure in modern obstetrics and its proper indications, risks and complications need to be studied for judicious usage and improvement in outcome.

Methods: A retrospective, record-based study was carried out over one and a half years at a tertiary care government hospital. All the patients who underwent emergency obstetric hysterectomy at the study centre during study period were studied. Labour room register, operation room register for emergency and elective cases, case records, referral slips and mortality register data were reviewed for the same and outcomes analysed.

Results: Total 33 patients underwent emergency obstetric hysterectomy, with the incidence observed at $0.21 \%$. The most common indications were atonic post-partum hemorrhage (42.4\%), uterine rupture (33.3\%) and morbidly adherent placenta (18.1\%). Prior cesarean section (36.4\%) and placenta previa $(15.1 \%)$ were the commonest predisposing factors associated with $\mathrm{PPH}$ and uterine rupture. Subtotal hysterectomy $(66.7 \%)$ was observed to be the preferred type of surgery. Out of total 7 maternal deaths that occurred, 4 (57\%) were because of disseminated intravascular coagulation.

Conclusions: There is increasing trend in the rate of obstetric hysterectomy along with rise in rate of previous LSCS, emphasizing the importance of the mode of delivery. Measures to reduce the rate of primary cesarean section are advisable.
\end{abstract}

Keywords: Obstetric emergency, hysterectomy, tertiary care centre, clinical profile, indications, predisposing factors, complications

\section{INTRODUCTION}

Over 500,000 women die each year due to complications of pregnancy and childbirth, a number that has remained relatively unchanged since 1990, when the first global estimates of the burden of maternal mortality were developed. What is further disturbing is the fact that most of the maternal deaths are preventable and despite the modernization of obstetric approach. ${ }^{1}$

Obstetric emergencies are the most common cause of maternal mortality worldwide, of which obstetric hemorrhage is the leading contributor. ${ }^{1}$ So, to control this menace of obstetric deaths, it is imperative that we manage the cases of obstetric hemorrhage effectively. Medical methods like oxytocin drip, methylergometrine, carboprost, misoprostol, conservative measures like condom balloon catheter and surgical interventions like B-lynch sutures, bilateral uterine artery ligation etc. have all been advocated to manage obstetric hemorrhage effectively, especially in a resource poor setting like ours. $^{2}$ With the established use and efficacy of the above mentioned conservative methods, need for emergency obstetric hysterectomy $(\mathrm{OH})$ has reduced to some extent, 
but still is the last resort to save maternal life in case of massive obstetric hemorrhage. ${ }^{3}$ In a rapidly developing situation, striking balance between spending excessive time on alternative techniques, leading to further delay and hemorrhage and moving to the definitive lifesaving hysterectomy becomes crucial. The maternal outcome, in terms of reduction in mortality and prevention of postoperative complications, greatly depends on the timely decision, surgical skill and speed of performing obstetric hysterectomy. ${ }^{4,5}$ In the developing world, preventable factors such as uterine rupture or uterine atony are the most common indications for obstetric hysterectomy; while conditions like postpartum hemorrhage, placenta accrete and placenta previa, apart from uterine rupture have been majorly responsible in our country. ${ }^{5,6}$ Off-late, placenta accreta has been observed to have become the leading indication for emergency peripartum hysterectomy, especially in developed world. ${ }^{7,8}$ This is due to the rising incidence of placenta previa or accreta associated with the increasing number of women with previous caesarean section. ${ }^{9}$

Though an uncommon surgery, it is an important procedure in modern obstetrics and its proper indications, risks and complications need to be studied for judicious usage and to make it even more successful, which will in turn help towards the larger aim of reduction in maternal morbidity and mortality. The present study was conducted with the objective of studying the incidence, indications, risk factors, post-operative complications and maternal and fetal outcome in the cases managed by emergency obstetric hysterectomy at a tertiary care centre.

\section{METHODS}

With the above objective in mind, a retrospective, recordbased study was carried out in the department of Obstetrics and Gynecology at the government tertiary health care center in central India from January 2016 to July 2017 i.e. one and a half years. The study population consisted of all the patients who underwent emergency obstetric hysterectomy at the study centre during mentioned period. Data of patients fulfilling following inclusion criteria were considered for the present study:

- All women admitted in the labour room who underwent obstetric hysterectomy during the study period

- All women who underwent hysterectomy for any indication during pregnancy (including those done for complications of extra uterine pregnancies or molar pregnancies or termination of pregnancy such as perforation and sepsis), labour or puerperium

- The women who delivered outside the study hospital and were referred for obstetric complications meriting hysterectomy and fulfilling the above conditions.

The data was obtained by reviewing the labour room register, operation room register for emergency and elective cases, case records, referral slips and mortality register. The records of all the patients who had undergone obstetric hysterectomy were analysed in detail. The clinical parameters studied were maternal age, parity, whether she was a registered case or referred case, obstetric history, route of termination of pregnancy, methods of induction of labour, indication of obstetric hysterectomy, type of obstetric hysterectomy, postoperative complications, maternal morbidity and mortality and perinatal outcome.

\section{Statistical analysis}

The data was analysed using SPSS (version 20); by applying chi-square test and un-paired t-test, as applicable.

Approval from Institutional Ethics Committee was obtained before start of the study. The data confidentiality was maintained throughout the study.

\section{RESULTS}

During the study period of 1 and half year, total 15,339 deliveries occurred, out of which 7487 (48.8\%) were cesarean deliveries and $7852(51.2 \%)$ were vaginal deliveries. A total of 33 obstetric hysterectomies were carried out during the study period, with the overall incidence of 1 in 465 deliveries i.e. $0.21 \%$. Out of 33 patients, more than half $(18,54.6 \%)$ were between $20-25$ years of age, followed by $8(24.2 \%)$ between $20-25$ years and $5(15.1 \%)$ between $30-35$ years. Majority of the patients $(23,69.8 \%)$ were gravida 2 and 3 and 6 patients $(18.1 \%)$ were primigravida.

Total 29 out of 33 patients were unregistered and only $12.15 \%$ i.e. 4 out of 33 patients were antenatally registered at the study hospital. Out of the 33 patients, 22 $(67 \%)$ patients belonged to rural areas and $11(33 \%)$ were from urban areas. Amongst the rural patients $(n=22), 14$ $(64 \%)$ were referred from rural hospitals $(\mathrm{RH}), 7$ (32\%) from primary health care centers (PHCs) and 1 patient was referred from private hospital in a rural setting. Amongst the 11 patients belonging to urban areas, 5 (45\%) were referred from a maternity trust hospital, 2 (18\%) patients from private hospital and 4 (36\%) were not referred from any hospital and sought care at the study hospital on their own.

Out of the 33 cases, $21(63.6 \%)$ patients were full term i.e. $>37$ weeks of gestation, 10 patients $(30.3 \%)$ were preterm i.e. $<37$ weeks of gestation and 2 patients $(6.1 \%)$ were $<28$ weeks of gestation. Amongst the 33 patients who underwent obstetric hysterectomy, 5 (15.2\%) had a vaginal delivery, $26(78.8 \%)$ had a cesarean section, whereas 2 patients $(6 \%)$ underwent laparotomy; both the laparotomies having been conducted for rupture uterus. Out of the 26 cesarean sections, 4 (12.1\%) were elective cesarean sections; the indication for all 4 being previous lower segment caesarian section (LSCS). Rest 22 
(66.7\%) were emergency caesarean sections, with obstructed labour (22.9\%), previous 1 LSCS with placenta previa in bleeding phase $(18.2 \%)$ and abruptio placenta $(18.2 \%)$ as the commonest indications. Two $(9.1 \%)$ elective caesarean sections were done in cases of previous LSCS with suspected uterine rupture (confirmed intra-operatively) and previous 2 LSCS in labour, and 1 $(4.5 \%)$ each was done in view of previous LSCS with twin pregnancy in labour, previous LSCS with preterm PROM with breech, previous LSCS with PIH with IUGR, previous LSCS with polyhydramnios in labour and primigravida with impending eclampsia with unfavorable cervix. The most common indication for obstetric hysterectomy $(\mathrm{OH})$ in this present study was atonic postpartum hemorrhage, which accounted for 14 (42.4\%) cases, followed by uterine rupture in $11(33.3 \%)$ cases. Six $(18.1 \%)$ cases had morbidly adherent placenta (placenta increta- 4 cases, placenta percreta- 2 cases), with 2 cases of traumatic post-partum hemorrhage (PPH) completing the numbers (Table 1).
Table 1: Various indications for emergency obstetric hysterectomy.

\begin{tabular}{|lll|}
\hline Indication & Number & Percentage \\
\hline Atonic PPH & 14 & 42.4 \\
\hline Uterine rupture & 11 & 33.3 \\
\hline Morbidly adherent placenta & 6 & 18.3 \\
\hline Traumatic PPH & 2 & 6 \\
\hline Total & $\mathbf{3 3}$ & $\mathbf{1 0 0}$ \\
\hline
\end{tabular}

As for the predisposing risk factors responsible for the mentioned conditions as indications, prior cesarean section $(>1)$ seen in $12 / 33$ cases $(36.4 \%)$ and placenta previa seen in $5 / 33(15.1 \%)$ were the commonest ones found significantly associated with $\mathrm{PPH}$ and uterine rupture. The other high risk factors were placental abruption, multiple pregnancy, obstructed labour with multiparity and prolonged labour (Table 2).

Table 2: Risk factors for major conditions necessitating emergency obstetric hysterectomy.

\begin{tabular}{|c|c|c|c|c|c|}
\hline \multirow{2}{*}{ Risk factor } & \multicolumn{3}{|c|}{ Major indications for $\mathrm{OH}$} & \multirow{2}{*}{$\begin{array}{l}\text { Number } \\
(n=33)\end{array}$} & \multirow{2}{*}{ Percentage } \\
\hline & PPH & Uterine rupture & Adherent placenta & & \\
\hline Previous LSCS & 3 & 5 & 4 & 12 & 36.4 \\
\hline Placenta Previa & 3 & 0 & 2 & 5 & 15.1 \\
\hline Placental Abruption & 4 & 0 & 0 & 4 & 12.1 \\
\hline obstructed labour with multiparity & 1 & 3 & 0 & 4 & 12.1 \\
\hline Multiple pregnancies & 2 & 0 & 0 & 2 & 6.1 \\
\hline Polyhydramnios & 1 & 0 & 0 & 1 & 3.0 \\
\hline Septic abortion & 0 & 1 & 0 & 1 & 3.0 \\
\hline Rudimentary horn pregnancy & 0 & 1 & 0 & 1 & 3.0 \\
\hline Puerperal sepsis & 0 & 1 & 0 & 1 & 3.0 \\
\hline
\end{tabular}

In most of the cases $(22,66.7 \%)$, subtotal hysterectomy was the type of preferred surgery, with total hysterectomy being performed in $10(30.3 \%)$ cases and hemihysterectomy $(3.0 \%)$ in a solitary case of rupture of rudimentary horn pregnancy.

Table 3 details the major post-operative complications observed in the present study. Fever, wound infections, severe anaemia, DIC and renal failure were the most common sequelae post-operatively. The patients had a mean of 25 days of hospital stay, prolonged owing to various mentioned complications.

There were $7(21.2 \%)$ maternal deaths noted in the study. Out of the 7 deaths, $4(57 \%)$ were because of disseminated intravascular coagulation (DIC) with shock (all 4 had atonic PPH with significant blood loss), 2 (28.6\%) patients were hepatitis E positive and died of encephalopathy with coagulopathy and $1(14.3 \%)$ patient died because of shock with respiratory failure.
Table 3: Major post-operative complications.

\begin{tabular}{|lll|}
\hline $\begin{array}{l}\text { Post-operative } \\
\text { complications }\end{array}$ & $\begin{array}{l}\text { Number } \\
(\mathbf{n = 3 3})\end{array}$ & $\begin{array}{l}\text { Percentage } \\
(\%)\end{array}$ \\
\hline Fever & 11 & 33.3 \\
\hline Wound infections & 6 & 18.2 \\
\hline Severe anemia & 6 & 18.2 \\
\hline DIC & 4 & 12.1 \\
\hline Renal failure & 3 & 9.2 \\
\hline Respiratory failure & 1 & 3 \\
\hline Vesicovaginal fistula & 1 & 3 \\
\hline Post-partum depression & 1 & 3 \\
\hline Total & $\mathbf{3 3}$ & $\mathbf{1 0 0}$ \\
\hline
\end{tabular}

Out of the 33 patients who underwent hysterectomy, 21 $(63.6 \%)$ patients had a live fetal outcome, 7 (21.2\%) patients delivered stillborns, $3(9.1 \%)$ patients had intra-uterine deaths (IUD) and $2(6.1 \%)$ patients delivered abortus. The perinatal mortality was around $30 \%$ (Figure 1). 
Amongst the 21 live babies, 7 babies needed NICU admission in view of hyperbilirubinemia, prematurity, sepsis and respiratory distress syndrome.

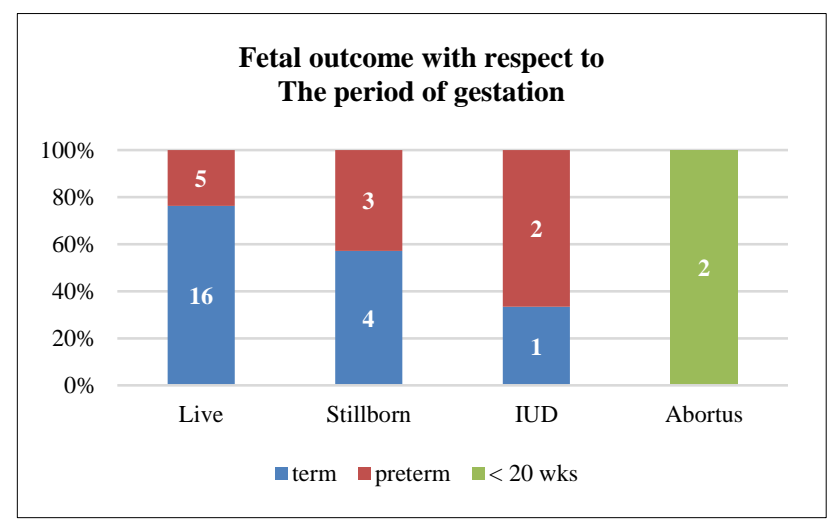

Figure 1: Fetal outcome with respect to the period of gestation.

\section{DISCUSSION}

Horatio Storer had performed the first obstetric hysterectomy way back in 1869 , a procedure that has since been used extensively to save maternal lives worldover. ${ }^{10}$ Knowledge of this operation and skill at its performance saves lives in various catastrophic obstetric conditions. The present study was conducted with the objective of studying the incidence, indications, risk factors, complications and outcomes in the cases managed by emergency obstetric hysterectomy.

The incidence of obstetric hysterectomy was observed to be $0.21 \%$ in the present study, which was similar to that of relevant studies by Anita $\mathrm{K}$ et al (0.26\%) and Shirodkar et al $(0.16 \%)$, while being lower in comparison with the observations of Singh R et al $(0.4 \%)$, Kumari A et al $(0.73 \%)$ and Koranne $\mathrm{P}$ et al $(0.4 \%) .{ }^{11-15}$ The incidence of obstetric hysterectomy following vaginal delivery and caesarean section were almost comparable, $0.42 \%$ in vaginal delivery and $0.44 \%$ in LSCS.

Majority of the patients $(69.8 \%)$ were para 2 and 3 . Parveen $\mathrm{M}$ et al reported maximum number of patients to be primiparas $(36 \%)$, in contrast to other studies including ours. ${ }^{11-16}$ There were no cases with gravida more than 4 in the present study, whereas Korejo et al had reported $45 \%$ patients as grand multiparas, with average parity of $5 .{ }^{17}$

The lower rate of grand-multiparity in the present study probably can be attributed to improved awareness regarding sterility and small family norms amongst the patients. Most of the patients $(88 \%)$ were unregistered and referred in emergency condition in moribund status from distant referral centers, mostly from rural areas. This is largely in agreement with most of the studies from similar setting, underlining the glaring gap in maternal health care provision in our country. ${ }^{11-16}$
Atonic PPH (42.4\%) was observed to be the commonest indication for obstetric hysterectomy in the present study, with abruptio placenta $(28.7 \%)$ being the most commonly associated factor in PPH followed by previous LSCS and placenta previa. Uterine rupture was the 2nd most common indication seen in 11/33 patients i.e. (33\%) and it was found to be significantly associated with scarred uterus, multiparity, obstructed labour and low socioeconomic status of the women. Most of the previous similar studies also have had them as the top 2 indications for obstetric hysterectomy. ${ }^{11,14,15}$ A few ones reported morbidly adherent placenta as one of the top 2 indications, depicting the rising trend of caesarean sections leading to abnormal placenta getting morbidly adherent, leading to hysterectomy. ${ }^{12,13,16}$ It was observed in 6 out of 33 patients $(18.1 \%)$ in the present study, with previous caesarean section being associated with $2 / 3 \mathrm{rd}$ of them. Rapidly increasing incidence of caesarean section was, infact, one major contributing risk factor in the present study, responsible in $36.4 \%$ of the patients; a finding in-line with available evidence. ${ }^{11-16}$ As the number of caesarean sections is increasing, the number of scarred uteri is also increasing. This exposes more and more gravid women to morbidity from uterine rupture, placenta previa and accreta, thus increasing the incidence of emergency obstetric hysterectomy. Stanco et al had observed previous cesarean section to be increasing the risk of obstetric hysterectomy by as much as 15-20 times way back in the late 80 s. $^{18}$

Subtotal hysterectomy cases significantly outnumbered total hysterectomy ones in the present study. This was comparable to most of the studies and also follows relevant guidelines, which have documented the preference for subtotal hysterectomy; as it leads to less blood loss, less chance of damage to the bladder/ureters and is faster to perfrom. ${ }^{11-16,19}$ However, in cases of morbidly adherent placenta, total hysterectomy is postulated to be relatively advantageous, as removal of the cervix will cause better hemostasis. ${ }^{20}$

Fever was the commonest post-operative morbidity followed by wound infections and wound dehiscence. This is consistent with the findings of previous research. ${ }^{11-17}$ Urinary tract infections, wound infections and respiratory tract infections have been reported to responsible for the fever. The mortality rate in the present study was observed to be $22.2 \%$, which is quite higher than previous similar studies like Anita K et al (9.7\%), Shirodkar et al (2.2\%), Singh R et al (1.96\%), Archana K et al $(5.35 \%)$ and Koranne et al $(6.66 \%) .{ }^{11-15}$ This may in part be attributed to the fact that the present study was conducted at a tertiary care government centre catering to a very large underserved populace over wide geography, leading to loss of precious time and increase in severity of cases, ultimately resulting in higher mortality. DIC was observed as the cause of death in majority of cases in the present study was also reported in the study of Anita $\mathrm{K}$ et al. ${ }^{11}$ Infact, Shirodkar et al and Singh $\mathrm{R}$ et al reported only 1 maternal death each, with the cause of 
that being DIC. ${ }^{12,13}$ Morbidity and mortality were due to the condition for which hysterectomy was done and not due to operative procedure. Maternal morbidity and mortality is increased while doing obstetric hysterectomy as most of the time patients are in adverse condition when they are referred. Availability of blood for transfusion and timely referral to a larger hospital go a long way in reducing morbidity and mortality among the patients with difficulties during labor. Availing antenatal care and identification of high risk cases are most important for avoiding catastrophic outcomes.

The perinatal mortality seen in our study was around $30 \%$ which was significantly lower than seen in previous similar studies, partly attributable to the excellent neonatal care provided at the study centre. ${ }^{15-17}$ The chances of fetal survival in the present study was expectedly seen to go up with the period of gestation. Amongst the 21 live babies, 7 babies needed NICU admission in view of hyperbilirubinemia, prematurity, sepsis and respiratory distress syndrome and were managed well there.

\section{CONCLUSION}

In conclusion, our results demonstrate an increasing trend in the rate of obstetric hysterectomy in parallel with an increasing rate of previous LSCS, emphasizing the importance of the mode of delivery. Measures to reduce the rate of primary cesarean section are hence advisable. Further research into means and types of those measures is recommended.

\section{Funding: No funding sources}

Conflict of interest: None declared

Ethical approval: The study was approved by the Institutional Ethics Committee

\section{REFERENCES}

1. Say L, Chou D, Gemmill A, Tunçalp Ö, Moller AB, Daniels J, et al. Global causes of maternal death: a WHO systematic analysis. The Lancet Global Health. 2014;2(6):e323-33.

2. Miller S, Lester F, Hensleigh P. CEU: prevention and treatment of postpartum hemorrhage: new advances for low-resource settings. J Midwifery Women's Health. 2004;49(4):283-92.

3. Najam R, Bansal P, Sharma R, Agarwal D. Emergency obstetric hysterectomy: a retrospective study at a tertiary care hospital. J Clin Diagnostic Res. 2010;4:2864-68.

4. Amarin Z. Subtotal Abdominal Hysterectomy. In Alkatout I, Mettler L, eds Springer, Cham. Hysterectomy: A Comprehensive Surgical Approach. 1st ed. Switzerland AG: Springer Nature; 2018:10931099 .
5. Zeteroglu S, Ustun Y, Engin-Ustun Y, Sahin G, Kamac1 M. Peripartum hysterectomy in a teaching hospital in the eastern region of Turkey. Eu J Obst Gynecol Repro Biol. 2005;120(1):57-62.

6. Chawla J, Arora CD, Paul M, Ajmani SN. Emergency obstetric hysterectomy: a retrospective study from a teaching hospital in North India over eight years. Oman Med J. 2015;30(3):181.

7. Engelsen IB, Albrechtsen S, Iversen OE. Peripartum hysterectomy-incidence and maternal morbidity. Acta Obstetricia et Gynecologica Scandinavica. 2001;80(5):409-12.

8. Zamzami TY. Indication of emergency peripartum hysterectomy: review of 17 cases. Arch Gynecol Obstet. 2003;268(3):131-5.

9. Yaegashi N, Chiba-Sekii A, Okamura K. Emergency postpartum hysterectomy in women with placenta previa and prior cesarean section. Int J Gynecol Obstet. 2000;68(1):49-52.

10. Parker NP, Bruner J. In: Rock JA, Jones HW, eds. TeLinde's Operative Gynecology. 9th edn. Philadelphia, PL: Lippinocott Williams and Wilkins; 2003:829.

11. Anita K, Kavita W. Emergency obstetric hysterectomy. J Obstet Gynaecol India. 2005;55(2):132-4.

12. Shirodker SD, Pandey A, Yadav S. Emergency obstetric hysterectomy: review at a tertiary care hospital. Int $\mathbf{J}$ Reprod Contracept Obstet Gynecol. 2016;5:3811-4.

13. Richa S, Arun N. Emergency obstetric hysterectomy-a retrospective study of 51 cases over a period of 5 years. J Obstet Gynaecol India. 2005;55(5):428-30.

14. Archana K, Bala SP. A Clinical Review of emergency obstetric hysterectomy. J Obstet Gynaecol India. 2009;59:427-31.

15. Koranne PS, Wahane A, Raut D, Bagdiya NJ, Nalat SA, Dhakne MG. An emergency obstetric hysterectomy in modern era: a conventional surgery still saves lives. Int J Scientific Study. 2015;3(1):72-7.

16. Parveen M, Manjeet K, Anju G. Peripartum hysterectomy-a five year study. J Obstet Gynaecol India. 2008;58(6):504-6.

17. Korejo R, Nasir A, Yasmin H, Bhutta S. Emergency obstetric hysterectomy. J Pak Med Assoc. 2012;62(12):1322-5.

18. Stanco LM, Schrimmer DB, Paul RH, Mishell Jr DR. Emergency peripartum hysterectomy and associated risk factors. Am J Obst Gynecol. 1993;168(3):879-83.

19. Scottish Obstetric Guidelines and Audit Project. The Management of Postpartum Haemorrhage: A Clinical Practice Guideline for Professionals involved in Maternity Care in Scotland 1998. Available at: healthcareimprovementscotland. org/his/idoc.ashx?docid=84ee51e6-d441...1. Accessed on $3^{\text {rd }}$ July 2019.

20. Singh R, Fay L, McKenna P. A 27-year review of obstetric hysterectomy. J Obstet Gynaecol. 2003;23(3):252-4.

Cite this article as: Mulik J, Vibhute T. Emergency obstetric hysterectomy: experience at a tertiary care centre in central India. Int J Reprod Contracept Obstet Gynecol 2019;8:3280-4. 